\title{
Conferência
}

\section{Os militares e a nação}

\author{
Benedict Anderson ${ }^{1}$
}

Da perspectiva de mais de meio século, hoje nós podemos ver claramente que a Segunda Guerra Mundial transformou drasticamente a função de várias forças armadas, ao mesmo tempo em que mudou seu papel político. Isto começou com a vasta conquista dos exércitos de Hitler e Hirohito e culminou com a enorme expansão militar da ex-União Soviética. No final da guerra, os Estados Unidos usaram armas nucleares pela primeira e última vez. Pela primeira vez na história, tinham sido criadas armas de efeitos tão terríveis e nefastos para o futuro da humanidade que nunca mais foram usadas, sendo mantidas apenas como uma "última opção defensiva".

É possível ver esta transformação de dois ângulos. Primeiro: todos os países envolvidos no conflito tinham ministros da Guerra; depois, todos foram renomeados ministros da Defesa. Este novo nome não foi apenas um eufemismo político hipócrita; refletia o processo de sacralização dos territórios nacionais, acelerado pela grande onda de descolonizações. Com pequenas exceções, a "conquista" do modo antigo tinha se tornado obsoleta. Ao contrário, muitas potências do pré-guerra, em diferentes escalas, tinham sido diminuídas por separatismos - URSS, Iugoslávia, Etiópia, Paquistão, Tchecoslováquia, etc. Se a "conquista" se tornara algo praticamente impensável, então, o que acontece com o papel e as funções dos militares?

1 Professor emérito de Estudos Internacionais da Universidade de Cornell e membro da Academica Americana de Artes e Ciências. 
Antes de entrar nesta questão, devemos ter em mente outro divisor de águas crucial representado pela Segunda Guerra Mundial. Já no final do século XIX, o ritmo das invenções tecnológicas relacionadas às forças militares estava se acelerando. A Primeira Guerra Mundial foi marcada pelo avião, submarino, tanques, gás venenoso, rádio, complexos de criptografia e assim por diante. Mas isto ocorreu em um ambiente ainda competitivo entre as potências. Já em 1940, o novato Japão podia construir um avião de combate (o Zero), melhor do que o das potências europeias inimigas. Contudo, os custos da competição se tornaram mais e mais intoleráveis, exceto para os gigantes Estados Unidos e URSS; e esta última saiu da corrida armamentista nos anos 1970.

O ponto crucial aqui é o rompimento entre a mentalidade militar que dominou o pensamento das potências do século XIX, tendo como modelos Prússia e França e, até certo ponto, o Reino Unido. Este "velho" pensamento dizia: Temos de monopolizar a produção de armas por nossos próprios industriais e cientistas. Alguém poderia argumentar que o ideal era uma força armada nacional, o que também se baseava em recrutamento de cidadãos. Hoje, poucos destes exércitos sobrevivem. A maioria dos militares no mundo é armada, sobretudo, do exterior, por um número relativamente pequeno de Estados ainda capazes de produzir armas "modernas" avançadas para exportação ou como "ajuda" estrangeira. Diferentemente do mundo do século XIX, o atual é marcado por um fluxo transnacional colossal de armas com os mais diferentes níveis de custo e sofisticação. Obviamente, os Estados Unidos são o maior exportador.

Como a maior parte dos Estados-nação contemporâneos acredita que um bom exército (pelo menos) é o verdadeiro distintivo da nacionalidade e, simultaneamente, vê cada vez menos necessidade de um exército conscrito, uma situação paradoxal e curiosa tem emergido. Há de se reconhecer que de todas as instituições similares ao Estado-nação, as forças armadas são as mais estandardizadas, em comparação, por exemplo, com as instituições judiciais, parlamentos, partidos políticos, chefes de Estado, etc. Quase todo Estado tem seus generais, coronéis, majores, capitães e oficiais não comissionados. Neste sentido, as forças armadas são as 
instituições mais distantes de qualquer ideia de singularidade nacional. Ao mesmo tempo, os militares costumam tomar a sério seu papel como símbolos exatamente desta singularidade nacional.

A verdadeira anomalia, no entanto, repousa em outro ponto. As forças armadas, como símbolo autopercebido da independência nacional, são, concomitantemente, as mais dependentes do mundo exterior. Claro que líderes militares inteligentes tentam diversificar sua dependência, lidando, por exemplo, com os Estados Unidos, a China, a Rússia, a Alemanha, a Suécia, o Reino Unido, até mesmo Israel, porém os custos são muito altos para os orçamentos nacionais.

Além disto, estes acordos têm duas consequências infelizes. Uma delas é a corrupção: a compra de armas obsoletas em troca de comissões e subornos. A outra é uma sutil manipulação por potências estrangeiras ou para fins políticos - "Você quer estes armamentos? Nós lhes damos de graça, mas você terá que..." ou mediante processos de treinamento, oferta de peças sobressalentes, reservas e armas com diferencial no tocante à sua modernidade tecnológica. As pressões são mais visíveis se você observa o impressionante número de bases militares estadunidenses ao redor do mundo. Isto seria impossível se muitos países pudessem produzir seu próprio armamento.

O outro lado destas novas condições pós-Segunda Guerra Mundial, ora especificadas, é que, intencionalmente ou não, a clássica divisão de trabalho do século XIX entre um "militar profissional" e uma polícia profissional, um para a guerra e a defesa nacional, e o outro para a supressão do crime doméstico, se tornou bastante confusa em muitos lugares, sobretudo onde "crime" é a linguagem usada para definir oposições políticas de vários tipos. Muitas das "guerras" mais sangrentas dos últimos cinquenta anos têm sido, pelo menos nominalmente, guerras civis domésticas, rebeliões, e assim por diante. Este foi o caso, em especial, durante a Guerra Fria, quando os militares decidiram que comunistas não eram verdadeiros cidadãos, mas agentes da URSS e do Partido Comunista.

Contudo, também há outras dificuldades visíveis. Poderíamos, por exemplo, tomar a questão do profissionalismo, a qual quase 
todos os exércitos tentam praticar. Em inglês, e talvez em muitos outros idiomas, "profissionalismo" tem dois significados contrários.

A) Se pensarmos em atletas profissionais, por exemplo, estamos nos referindo a jogadores de destaque que ganham altas somas de dinheiro mediante a venda das suas habilidades para cidades, corporações ou conglomerados da mídia. Lealdade está fora de questão. Podemos facilmente pensar nestes profissionais como mercenários nômades, que ocasionalmente, nas Olimpíadas ou na Copa do Mundo, tiram algum tempo para representar suas nações. Porém, militares raramente se percebem como mercenários.

B) Profissionais designam também aquelas pessoas que usam suas habilidades para servir, em tese, abnegadamente, seus clientes. Os exemplos óbvios são médicos (que devem tentar curar qualquer doente), advogados (que devem defender qualquer pessoa com problemas legais), professores (que devem ensinar qualquer estudante). Esta ética de serviço é socialmente reconhecida por títulos profissionais como Doutor ou Professor. Neste sentido, o profissional é identificado por seus "clientes", com os quais uma ligação moral é essencial. O médico irá ajudar até mesmo um gângster que tenha levado um tiro, o advogado defenderá um conhecido bandido e o professor ensinará estudantes preguiçosos e desagradáveis. No entanto, estes são clientes, de certa maneira, "claros e pessoais", a quem o profissional pode nomear facilmente. A ideia básica é "serviço" composto por vários juramentos.

O problema moral e político para os militares é que seus "clientes" não são indivíduos, mas uma série de abstrações, instituições coletivas e comunidades imaginadas, as quais estão frequentemente em conflito entre si. Por exemplo, militares podem ter de escolher entre a lei da Constituição, maiorias eleitorais, governos, a nação, o líder formal do Estado e assim por diante. Em geral, as condições em que todos estes "clientes" se sobrepõem uns aos outros, eliminando o conflito, são a exceção, não a regra. Militares não podem ser responsabilizados por esta tensão, visto que ela está no coração do Estado-nação moderno e pode conduzi-los a diferentes conflitos, bem como a impasses. 
Segundo: mesmo nos "bons tempos" antes da Segunda Guerra Mundial, era sabido que muitos exércitos "combatiam um inimigo" apenas raramente. Seguindo os modelos francês e prussiano, grande parte da vida ativa de um soldado profissional transcorria em paz entre educação e treinamento, o qual tinha de ser constantemente atualizado. Às vezes, parte desta educação e treinamento era feita no exterior, geralmente em países exportadores de armas, como os Estados Unidos. Neste cenário, a promoção era comumente baseada em testes acadêmicos e performances práticas e, de fato, era bem demorada. Assim que uma guerra começava, os critérios mudavam rapidamente, isto é, conforme o êxito no campo de batalha ou planejamento brilhante. Hoje, o problema na maioria dos países "sacralizados" é que a guerra raramente ocorre nas fronteiras do Estado-nação. O resultado disto é tédio e geralmente intrigas étnicas e religiosas (o profissionalismo, em princípio, rejeita critérios externos como etnia ou identidade religiosa).

Tipicamente, golpes surgem em condições de crise em que os clientes destes profissionais se opõem uns aos outros: o governo rejeita eleições, o presidente desrespeita a constituição, os partidos políticos democráticos dividem a nação, e assim por diante. Contudo, regimes militares raramente se mantêm por longo tempo (Burma é a grande exceção que confirma a regra!). A razão é bem simples: se os militares tomam o poder para resolver uma disputa política doméstica, se deparam com um óbvio "cul de sac". Se eles resolvem os problemas que deram origem à crise, por que permanecem no poder? Se eles não conseguem resolver a crise, por que continuam no poder? Talvez a história do governo militar no Brasil ofereça um bom exemplo disto.

Todavia, o grande problema para os regimes militares é outro. Instituições militares convencionais possuem uma hierarquia bastante clara. Um general deveria ter mais de 50 anos, um coronel, mais de 40, etc. O general tem seu salário, o coronel tem um salário menor; o general detém muita experiência em assuntos militares, o coronel, menos; o general se graduou na Universidade $\mathrm{X}$, o coronel, na Academia Y. O general deve se aposentar, digamos, aos 60; enquanto o coronel que não consegue chegar a general-de-brigada deve deixar o exército, digamos, aos 50. Tudo, 
portanto, está em ordem. Depois de um golpe sério, no entanto, esta disciplinada hierarquia começa a se enfraquecer internamente. O coronel indicado para administrar o Banco Nacional receberá um salário condizente com o do chefe de um grande banco, que é mais alto do que os salários de muitos generais. O tenente-coronel responsável pelas alfândegas ficará acostumado com os subornos que os oficiais de alfândega comumente exigem. O oficial encarregado do monopólio de petróleo do governo anterior terá um estilo de vida mais ostentoso que muitos dos seus superiores. Em outras palavras, a clara hierarquia do exército anterior ao golpe é implacavelmente solapada pela distribuição de oficiais em empregos com critérios completamente diferentes de promoção, salários, benefícios, e assim por diante. Em consequência, o profissionalismo é desestabilizado pela nova divisão de trabalho e suas recompensas. Esta é uma das razões pelas quais regimes militares não duram muito tempo, pelo menos se os militares consideram a si mesmos como profissionais.

Dois últimos pontos. Primeiro, a Prússia e a França criaram uma nova e impressionante divisão de trabalho (em condições normais) entre os militares e a polícia; uma com objetivos externos e a outra internos. Esta divisão de trabalho aumentou muito o prestígio das forças armadas, enquanto a polícia passou a ser, muitas vezes, odiada, pelo menos pelas classes mais baixas (nas quais os exércitos recrutam dezenas de centenas de soldados temporários). Entretanto, na era pós-Segunda Guerra Mundial, esta divisão do trabalho, clara, em tese, se tornou, frequentemente, confusa. Em muitos países, tal confusão levou os militares a se tornarem um tipo de superpolícia. A inteligência militar se expande de maneira ampla no país, enquanto externamente tende a se atrofiar. Por que isto aconteceu? A principal causa é o rápido, incessante e caro desenvolvimento da tecnologia militar (militares precisam estar o mais atualizados possível). Este processo ilimitado faz com que seja necessário que pelo menos oficiais não comissionados obtenham um alto nível de educação, treinamento, conhecimento científico, habilidades com computadores e conhecimentos em pelo menos uma língua estrangeira. No entanto, este maior nível de educação está, de formas variadas, em conflito com a velha ideia nacionalista de 
exército cidadão e recrutamento geral masculino. Em países "avançados", o recrutamento está virtualmente extinto, enquanto no hemisfério sul vem se tornando cada vez mais raro. Inevitavelmente, isto faz com que as forças armadas estejam ainda mais distantes da juventude nacional do que antes, aumenta o desemprego para jovens adultos e enfraquece a solidariedade nacional.

Segundo, tenho tentado mostrar que o "êxito" do nacionalismo em escala global, começando pela Liga das Nações e continuando com as Nações Unidas, tem sido um fator-chave na sacralização do território nacional. A quase impossibilidade de expansão militar das fronteiras nacionais tem reduzido a capacidade militar de brilhar como um defensor da soberania nacional, imagine conduzir anexações dos territórios de outros Estados nacionais. Ninguém contempla seriamente a ideia de invadir o Brasil ou o Peru, a Tailândia, a Gana ou a Estônia. Então, o que as forças armadas podem fazer para "servir a seus clientes"? Todos nós estamos cientes das "missões cívicas", em que engenheiros militares desempenham um importante papel na construção de trabalhos públicos e têm relevante intervenção na ocorrência de desastres naturais.

Também estamos cientes de que as forças armadas cedem oficiais e soldados para diversas missões de paz da ONU (onde atuam mais como polícia do que exércitos tradicionais). É verdade que, graças à Guerra Fria, as forças armadas brasileiras - como muitos dos seus parceiros sul-americanos - foram encorajadas a acreditar que insurreições domésticas armadas estavam sendo conduzidas por pessoas que não eram verdadeiros concidadãos, mas espiões e agentes do "comunismo internacional". A partir deste cenário, foram adotadas práticas contra concidadãos que eram típicas da polícia, tortura, execuções ilegais, etc., todas elas violando a Convenção de Genebra (Não há nenhuma convenção global que controle as forças policiais). Agora que o "comunismo internacional" desapareceu, qual seria o papel profissional dos exércitos sul-americanos, que consomem orçamentos tão altos?

o perigo que deve nos preocupar é o declínio do profissionalismo que se observa em muitos países. A proliferação de impérios de negócios militares é sinal de uma tendência negativa. Com frequência, estas empresas (algumas vezes verdadeiros monopólios) 
são mantidas porque suprem as forças armadas com recursos financeiros que estão fora do orçamento e que não servem ao povo, encorajam a corrupção, expandem uma indesejável imunidade legal e assim por diante.

A tragédia com a qual temos nos preocupado é delineada pelo grande número de militares de países membros das Nações Unidas que nunca lutaram verdadeiramente contra uma nação estrangeira, mas já mataram um sem-número dos seus próprios cidadãos. As forças armadas deveriam pensar mais, e mais cuidadosamente, a respeito da sua honra, das necessidades dos seus clientes e sobre seu próprio papel histórico-político no último meio século. É realmente necessário uma força militar brasileira grande e cara? As forças armadas precisam considerar a possibilidade de que, no fim, venham a acreditar que seu primeiro cliente... são elas mesmas!

Tradução: Camila Alves da Costa 